Images dans le monde ibérique et ibéricoaméricain

9 | 2016

Innovations politiques et culturelles dans les pays andins

\title{
Creación audiovisual en comunidades étnicas del suroccidente colombiano
}

\section{Angélica Mateus Mora}

\section{(2) OpenEdition}

Journals

Edición electrónica

URL: http://journals.openedition.org/agedor/1262

DOI: 10.4000/agedor.1262

ISSN: 2104-3353

Editor

Laboratoire LISAA

Referencia electrónica

Angélica Mateus Mora, « Creación audiovisual en comunidades étnicas del suroccidente colombiano ", L'Âge d'or [En línea], 9 | 2016, Publicado el 01 marzo 2016, consultado el 05 mayo 2019. URL : http:// journals.openedition.org/agedor/1262; DOI : 10.4000/agedor.1262

Este documento fue generado automáticamente el 5 mayo 2019.

L'Âge d'or. Images dans le monde ibérique et ibéricoaméricain 


\title{
Creación audiovisual en comunidades étnicas del suroccidente colombiano
}

\author{
Angélica Mateus Mora
}

\section{Las pantallas "marginales"}

1 Para el espectador de cine comercial, el acto de asistir a una sesión cinematográfica se ha convertido en una acción banal, en la que se siguen ciertas normas y estructuras de organización garantizadas la mayor parte del tiempo de principio a fin. Sin embargo, en la actualidad podemos encontrar todavía un espectador que asiste a un tipo de proyección al que podríamos llamar "marginal", en el que las normas y estructuras habituales desaparecen casi por completo. En este marco se inscribe una parte de los espectadores del cine digital producido actualmente en los Andes colombianos. Para determinar las características de estas proyecciones vamos a partir de dos ejemplos:

\section{Sesión de cine 1: Cauca}

2 Ante la inexistencia de una sala de cine, se ha esperado la oscuridad de la noche para exhibir un audiovisual. De esta proyección ha quedado un breve instante capturado en una fotografía. En ella, la atención del público se concentra en una pantalla que ha sido dispuesta en un muro exterior de una edificación y que presenta claramente a un hombre que participa en una movilización social. Los espectadores se han instalado como han podido delante de esta pantalla. En sillas plásticas, sobre la hierba, en el sillín de una motocicleta o simplemente han permanecido de pie. Algunos de ellos asisten en familia. Entre los niños, el más pequeño encuentra una ocasión para refugiarse en el seno de su madre. 


\section{Sesión de cine 2: Valle del Cauca}

3 Bajo la oscuridad de la noche, decenas de personas afrocolombianas de todas las edades se congregan alrededor de una pantalla instalada muy probablemente en la plazoleta principal de un pueblo. La realizadora colombiana María Isabel Ospina está presente en esta proyección y más tarde, para concluir su documental Hecho en Villapaz (2014), introducirá algunos planos capturados en este momento. Es a partir de esos encuadres que podemos describir esta sesión de cine. Las imágenes en movimiento que fueron allí proyectadas alternan con diversos planos sobre rostros atentos, risueños, orgullosos, sorprendidos o emocionados; cuerpos acomodados en sillas, árboles o cualquier otro espacio disponible. Todo esto rodeado de una paleta de colores vivos que resaltan en la oscuridad. Las imágenes no dejan indiferentes a los espectadores en ningún instante, como lo indican los ceños fruncidos, los gritos, los saltos o las carcajadas estruendosas con las que se fusiona el sonido de la proyección.

Estas dos sesiones cinematográficas tuvieron lugar en los Andes colombianos, más precisamente en el suroccidente del país y dan cuenta de una situación que hoy es frecuente no sólo en esta parte del territorio colombiano sino en diversas regiones de América Latina. Como veremos más adelante, la primera de ellas remite a la historia de la comunicación audiovisual en el seno de la comunidad indígena Nasa del Norte del Cauca, y la segunda a la primera experiencia cinematográfica producida por un afrocolombiano en Villapaz, un corregimiento ${ }^{1}$ de la municipalidad de Jamundí, en el departamento del Valle del Cauca.

5 En los dos casos, la proyección tiene lugar en un espacio abierto que no posee, desde ningún punto de vista, el habitual "confort" de una sala de cine. Las imágenes proyectadas en estas pantallas adquieren igualmente un carácter marginal no sólo por el hecho de ser presentadas en lugares otros que la sala de cine tradicional. Sus creadores forman parte de los llamados grupos "subalternos", aquellos que se han dejado en las "periferias" de la sociedad y que además se interesan por las temáticas que no suscitan ningún interés entre los grandes productores audiovisuales ya sea por desinterés o por desconocimiento, y que remiten a sus culturas, su historia, su comprensión del mundo, o a los problemas que los afectan.

6 Con Alquimia Peña podemos decir que estas temáticas forman parte de aquellas que "han permanecido prácticamente invisibilizadas por la propia dinámica excluyente de la producción y difusión del cine destinado a la gran pantalla"2. Estas imágenes que han podido o podrían ser referenciadas como parte del "cine popular", del "cine alternativo", de las imágenes producidas por las "cámaras de la diversidad", por el "cine y audiovisual comunitario" o por el "cine digital de provincias", desarrollan no sólo relatos propios, sino que también crean sus propias modalidades de producción y circulación y además generan sus propias funciones sociales. Veamos a continuación cómo surgen estas experiencias y cómo están organizadas.

\section{La experiencia del norte del departamento del Cauca}

7 Como lo hemos indicado, en el Norte del Cauca vive una parte del pueblo nasa, que es el segundo grupo indígena más numeroso de Colombia. En su territorio, en el año 2005, nace la experiencia audiovisual del Tejido de Comunicación y Relaciones Externas para la Verdad y la 
Vida. Esta se inscribe en un contexto histórico mucho más amplio que engloba el del movimiento indígena colombiano. En efecto, desde los años setenta, época que corresponde al nacimiento del CRIC (Consejo Regional Indígena del Cauca), este movimiento social integra el cine como un medio que permite visibilizar sus luchas y en particular aquellas organizadas con el fin de recuperar las tierras que le han sido usurpadas. En ese entonces la organización recibía o invitaba cineastas que apoyaban sus demandas ante la sociedad o el Estado.

El 10 de junio de 1993, el gobierno colombiano a través del decreto 1088, permite a los Cabildos, es decir los organismos que representan la autoridad de los territorios indígenas, organizarse en asociaciones. La Asociación de Cabildos Indígenas del Norte del Cauca $(\mathrm{ACIN})^{3}$ nace un año después. Desde sus inicios, esta asociación ha otorgado un gran valor a la comunicación en su proyecto de organización llamado Plan de vida ${ }^{4}$. Por esta razón, en el año 2005 decide crear un espacio de comunicación al que le da inicialmente el nombre de "programa de comunicación" y a él se asocia un grupo de jóvenes de diferentes resguardos ${ }^{5}$ del departamento.

La asociación propone una formación inicial a estos jóvenes que durará dos años y que se adaptará a cada uno de los dominios en que ellos se desempeñarán: Internet, radio, video y órganos de comunicación escrita ${ }^{6}$. Esta formación llamada "Escuela de Comunicación" se enriquece posteriormente a través de sesiones de formación de carácter puntual e informal ${ }^{7}$ y promoverá prácticas de trabajo grupal que articulen el conjunto de elementos del proyecto. Inscrito en un largo proceso de organización estructurada en cuatro etapas: Resistencia, Tierras y cultura, Autonomía y Alternativa, este proyecto aparece como el heredero de una estrategia de comunicación destinada a articular, como veremos más adelante, las formas tradicionales de comunicación del pueblo nasa con las formas y medios de comunicación moderna. En lo que se refiere a la creación audiovisual, vemos que se ha seguido un largo proceso antes de pasar a una producción audiovisual propia, a través de la cual el pueblo nasa se expresa por sí mismo.

La realización de videos comienza rápidamente y está motivada en gran parte por el interés que muestra la comunidad ante el proyecto de comunicación audiovisual. Así, durante el proceso de formación de los jóvenes nasa que decidieron comunicar a través del video, las comunidades de las que ellos forman parte les piden que filmen el proceso organizativo. Esta demanda es aceptada:

(...) y bueno, desde ahí ya empezamos a hacer unos videos. Desde ahí, la comunidad nos decía: Miren ustedes. Ya que se están capacitando, ¿por qué no realizan este documental que necesitamos tenerlo como archivo? Necesitamos tener este material para mostrarlo más adelante a nuestros hijos y para mostrar en otras partes el proceso organizativo. ${ }^{9}$

11 Crítica frente a los modos clásicos de producción de la información, la ACIN decide cambiar la denominación inicial dada al proyecto de comunicación audiovisual. La asociación considera que el término "programa", que es frecuentemente utilizado por los grupos de comunicación privada, remite a una forma de comunicación que limita la libertad de expresión y que defiende unos valores y principios contrarios a los que ella quiere defender. Inspirándose en el tejido tradicional del pueblo nasa, la jigra, el nombre del proyecto se cambia por el de Tejido de Comunicación y Relaciones Externas para la Verdad y la Vida ${ }^{10}$, sugiriendo de esta manera una analogía ente el acto de tejer y el acto de comunicar. 

del documental Hecho en Villapaz. Sin embargo, Víctor González Urrutia, el creador de las imágenes proyectadas en ese momento ante la comunidad, había decidido hacer este tipo de proyecciones por lo menos 7 años atrás, después de la premier de Amor sin perdón, su primera película, donde cuenta la historia de una decepción amorosa. En esa ocasión el público se reunió en el salón comunal atraído por un cartel creado por uno de sus 
hermanos, "diciendo que había premier en Villapaz"16. El creador del filme afirma que en ese momento no tenía la intención de difundir su trabajo: "Pues la película la hicimos pa' tenerla con mi papá, y pa' que la gente la vea, pero no todavía" ${ }^{17}$. Sin embargo, animado por su familia accedió y se encontró en un salón que no tenía la capacidad suficiente para recibir al público que estaba dispuesto a ver su trabajo, a través de un televisor que sólo tenía 21 pulgadas y un minicomponente prestados por su familia ${ }^{18}$.

Para la realización de Amor sin perdón, el creador disponía de la ayuda de su padre, un tío, un primo que se convirtieron en actores para la ocasión, y de la cámara de un celular Nokia, que fue uno de los primeros teléfonos móviles que llegaron a su corregimiento y que permitían capturar imágenes en movimiento, pero que ya en otros lugares eran considerados como obsoletos ${ }^{19}$. Pese a la mala calidad de la imagen el público quedó cautivado, "y cuando terminó la película, pues fueron una lluvia de aplausos (...) lo más bonito de todo, cuando vi que toda la gente del pueblo aplaudía"20.

19 A partir de ese momento, este joven afrocolombiano de 22 años, que hasta entonces trabajaba como albañil, haciendo retratos o pintando, se deja fascinar por esta nueva tecnología y decide combinar su trabajo con la realización de películas en las que participarán otras personas de la comunidad. Esta decisión va a implicar a su vez otros cambios en si vida. El primero tiene que ver con la creación de relatos. Víctor González hasta ese entonces era conocido en su entorno no sólo por su trabajo en la construcción, sino también porque le gustaba escribir historias en las que combinaba la fantasía y la realidad. Con la llegada de este teléfono móvil, se produce una especie de transposición. Ahora las historias que escribe se construyen a través de las imágenes en movimiento: “Todo empezó porque yo escribo desde niño fábulas y cuentos y quería convertir estos escritos en videos." ${ }^{21}$

En Villapaz más de la mitad de la población es afrocolombiana, y las principales actividades económicas son la agricultura, la ganadería y la explotación minera. Sin embargo, se trata de un territorio desconocido pese a su cercanía con Cali, la capital del departamento, marcado no sólo por el desplazamiento forzado de la población, sino también por los escasos ingresos, el desempleo, la mala cobertura social y educativa. El comienzo de esta experiencia coincide por otra parte, con una toma de posición frente a esta situación que afecta en particular a los jóvenes del corregimiento, quienes, ante la imposibilidad de encontrar un empleo o de seguir una carrera universitaria, optan por desplazarse a otra región del país. Para Víctor González, el cine aparece como una opción que le permitirá no sólo enfrentar esta situación, que se asocia al sentimiento de incertidumbre provocado por los efectos del narcotráfico o la violencia en la región, sino también mostrar a la comunidad que otras opciones son posibles.

Cuando este joven se lanza en la realización de filmes, lo hace de manera espontánea e intuitiva y sin tener ninguna noción en la materia. Asumirá la dirección, la financiación, la fotografía, el sonido, el montaje, la promoción y la difusión. "Cuando empecé fue de una manera muy fortuita, sin saber. Sólo quería saber si se lograba el objetivo, pero sin un conocimiento de los planos, del encuadre, de los movimientos de la cámara. No, simplemente quería registrar lo que yo quería ver, no pensaba en plano, ni nada de eso (... )". Como lo indica Camilo Aguilera Toro, su formación comenzará en el año 2010 asistiendo a cursos de fotografía organizados por la Fundación Plan ${ }^{22}$, donde escuchará hablar por primera vez de la escala de planos y de la importancia del Internet para su proyecto, o también a través de talleres dictados por reconocidos cineastas colombianos como Víctor Gaviria. 
Para González resulta también fundamental la lectura de libros sobre cine que le han regalado algunos amigos o los tutoriales que encuentra en YouTube. Con el paso del tiempo, ahora tiene claro que los diferentes elementos que componen sus películas tienen un nombre específico, que hace parte de un lenguaje "institucional" utilizado por la academia o por los cineastas profesionales. Sin embargo, a él le resulta complejo ajustar su estilo de trabajo con esa norma o basarse en referentes. Primero porque en sus películas aparecen los mitos, las leyendas o las historias que se cuentan en Villapaz y en ellas se refleja la forma como allí se cuentan esos relatos. Segundo, porque la mayoría de sus películas están en su cabeza a la hora de rodar y hay una mínima división de trabajo para su realización ${ }^{23}$. Tercero porque considera que al seguir un modelo o referente se " termina copiando el mismo modelo, aunque lo haga con otras palabras" ${ }^{24}$.

Villapaz forma parte de los pueblos y corregimientos colombianos que hoy todavía no poseen una sala de cine. Para la proyección de sus películas, "Víctor sigue poniendo carteleras en la plazoleta principal o buscando salones comunales para poder mostrar sus películas/"25 De hecho, la primera vez que asiste a una sala de cine remonta al año 2013 para la proyección de Anina, una película colombo-uruguaya realizada ese mismo año por Alfredo Sordeguit, es decir cinco años después de haber proyectado Amor sin perdón.

En diferentes artículos y estudios se le ha presentado como "uno de los realizadores más prolíficos del país" y en ellos se destaca la rapidez con que crea sus filmes. A los cuatro años de haber iniciado su proyecto cinematográfico ya contaba con dieciocho películas y tenía varias en proceso de realización ${ }^{26}$, en la actualidad ya suma 32. Entre ellas se encuentran diversos largometrajes, cortometrajes, documentales, ficciones, filmes de animación o experimentales. En ellos utiliza diversos géneros, y la gran mayoría los crea a partir de su propia iniciativa, inspirándose en las costumbres, tradiciones, creencias y problemas que afectan al corregimiento tales como la presencia de actores armados o la influencia de las iglesias cristianas o evangélicas; una minoría han sido películas de tipo institucional.

Excepcionalmente el trabajo de Víctor González ha sido presentado en salas de cine. La mayor parte de su producción ha sido proyectada mediante un video-proyector a través de pantallas construidas con listones de madera y sábanas blancas, en espacios abiertos, bajo la oscuridad de la noche. Proyecciones que recuerdan los inicios de la historia del cine en Colombia, cuando se utilizaban pantallas de doble faz y que el público se disponía a lado y lado de la pantalla para poder ver la película. Aunque Víctor González ha sido reconocido por varios profesionales del cine, invitado a varios festivales tanto en Colombia como en el extranjero, y visitado por diversos medios de comunicación, continúa filmando con cámaras prestadas pero con un objetivo muy claro: permanecer en Villapaz para contar y conservar su cultura afro.

\section{Conclusión}

Estas dos experiencias fílmicas del suroccidente colombiano dan cuenta de las múltiples posibilidades que ofrecen las nuevas tecnologías digitales en las regiones olvidadas por las grandes productoras audiovisuales. No se trata únicamente de adquirir conocimientos técnicos relativos a los medios de audiovisuales, sino de proponer nuevas alternativas de comunicación. Vemos que cada experiencia remite a un proceso diferente que está ligado a la especificidad cultural en la que se encuentra inserta. En cada caso se crean no sólo 
relatos propios, sino también modalidades propias de producción y circulación de los trabajos. En ambos casos se le otorga al audiovisual una función social acorde con las necesidades de la población a la que está dirigida su producción. Estas iniciativas, creadas por "realizadores no profesionales" contribuyen a fortalecer la libertad de expresión, los lazos de la comunidad, las identidades, y a posicionar social y políticamente las poblaciones representadas que, como lo dijimos al comienzo, siguen siendo marginalizadas.

\section{NOTAS}

1. En Colombia, el término "corregimiento" corresponde a una unidad administrativa más pequeña que una municipalidad.

2. Cf. GUMUCIO DAGRON Alfonso, Cine comunitario en América Latina y el Caribe, La Habana, Fundación del Nuevo Cine Latinoamericano, 2012, p. 15.

3. La Asociación de Cabildos Indígenas del Norte del Cauca - ACIN CXAB WALA KIWE (Territorio del gran pueblo) tiene su sede en el municipio de Santander de Quilichao, al norte del departamento del Cauca, reúne 14 resguardos y 16 cabildos. Estos últimos se organizan alrededor de siete proyectos y cada uno tiene un representante; la reunión de estos conforma la Consejería de la ACIN.

4. El Plan de vida se orienta sobre la base de principios tales como la espiritualidad, la reciprocidad, la integralidad del cosmos y el respeto de la tierra; a través de él se defienden valores como la unidad, el territorio, la cultura y la autonomía. Forman parte de este plan dos componentes en los cuales puede participar el conjunto de la comunidad: uno es político y el otro técnico. El primero comprende entre otros los congresos, las movilizaciones, los proyectos comunitarios y las asambleas; el segundo, está representado por cinco tejidos de vida: economía y ecología; pueblo y cultura; justicia y harmonía; defensa de la vida; comunicación y relaciones externas.

5. Entidad administrativa y territorial de origen colonial, que reagrupa a varias familias indígenas.

6. Actualmente en cada uno de estos dominios hay un medio de comunicación. Radio Payu'mat enriquece el trabajo de Radio Nasa y de Voces de nuestra tierra; nasaacin.org; la revista El carpintero.

7. Dora Muñoz, entrevista, Santander de Quilichao, 18 de agosto de 2008.

8. Cf. POLANCO URIBE Gerylee, AGUILERA TORO Camilo, Luchas de representación prácticas, procesos y sentidos audiovisuales colectivos en el suroccidente colombiano, Santiago de Cali, Universidad del Valle, Programa editorial, 2011, p. 68-69.

9. Dora Muñoz, entrevista, Santander de Quilichao, 18 de agosto de 2008.

10. En adelante Tejido de Comunicación

11. "Frecuentemente, los maestros de escuela adquieren filmes documentales [en el Tejido de comunicación] para hacer foros y debates sobre temáticas diversas. En este contexto surgen nudos, es decir personas claves para la comunidad: un profesor o un miembro de la guardia indígena. Simbólicamente, estas personas se convierten en el puente entre la comunidad y el Tejido de Comunicación. El nudo informa sobre lo que sucede en la comunidad (...)" (Isadora Cruz, entrevista, 18 de agosto 2008)

12. Isadora Cruz, entrevista, 18 de agosto 2008. 
13. Ibid.

14. Alfonso Gumucio Dagron señala en su texto Aproximaciones al cine comunitario que en "América Latina se produce, desde el inicio de la década de 1980, un quiebre entre el cine realizado por cineastas interesados en la realidad social - muchos de ellos militantes en causas políticas progresistas -, y los procesos de producción y difusión audiovisuales que llevan adelante las comunidades para interpelar su propia realidad social, política y cultural" (cf. GUMUCIO DAGRON, op. cit. p. 28).

15. Cf. VELLEGGIA Susana, La máquina de la mirada: los movimientos cinematográficos de ruptura y el cine política latinoamericano en las encrucijadas de la historia, Quito, CIESPAL, 2010.

16. GONZÁLEZ Luisa, "Cine digital de provincias: el caso colombiano" in Visaje, agosto 20, 2015. Documento electrónico [http://revistavisaje.com/?p=4682] (última conexión: 19/11/2017).

17. Transcripción hecha a partir del documental Hecho en Villapaz.

18. La senda equivocada (2009) también fue proyectada en las mismas condiciones.

19. CRUZ HOYOS Santiago, "Víctor Alfonso González, el cineasta que empezó a hacer películas con su celular" in El País, Noviembre 1, 2015. Documento electrónico [http://www.elpais.com.co/ elpais/cultura/noticias/pelicula-victor] (última conexión: 19/11/2017).

20. GONZÁLEZ Luisa, op. cit.

21. GONZÁLEZ Luisa, op. cit.

22. Esta fundación está presente en Colombia desde 1962.

23. En la realización de El mal de los 7 días (2011), Víctor González trabajó con un equipo de producción completo (asistente de dirección, dirección de fotografía, producción ejecutiva, sonido, dirección de arte, producción de campo, mezcla de audio y sonido).

24. GONZÁLEZ Luisa, op. cit.

25. MELO TOBON Andrea in [http://www.bacanika.com/cultura/cine-y-tv/item/cineconcreto.html] (Documento electrónico, última conexión: 24/11/2017).

26. Cf. POLANCO URIBE Gerylee, AGUILERA TORO Camilo, Luchas de representación..., op. cit. En este trabajo Camilo Aguilera presenta un análisis muy completo de la producción fílmica de González Urrutia hasta el año 2011.

\section{RESÚMENES}

Marcada por la presencia de una parte de la población afrocolombiana y de varias comunidades indígenas, la región del suroccidente de Colombia se caracteriza por su diversidad étnica y cultural. En esta región, la adquisición de las nuevas tecnologías numéricas ha permitido, desde hace algunos años, la emergencia de diversas formas de producción fílmica. En nuestro texto presentamos dos de las iniciativas más conocidas en la región: la de Tejido de Comunicación, desarrollada en una comunidad indígena, y la de Víctor Alfonso González, en el ámbito afrocolombiano. Damos cuenta del proceso de creación de estas dos experiencias y del sentido que cada una de ellas tiene en el seno de las comunidades filmadas.

Marquée par la présence de populations afro-colombiennes et indiennes, la région sudoccidentale de la Colombie est caractérisée par une grande diversité ethnique et culturelle. Depuis quelques années, l'arrivée de nouvelles technologies numériques a permis dans cette région l'émergence de diverses formes de production de films. Dans ce texte nous présentons deux expériences parmi les plus connues de la région : celle du Tissu des Communications, créée 
par une communauté indienne, et celle de Víctor Alfonso González, dans l'espace afro-colombien. Nous retraçons le processus de création de ces deux expériences et examinons le sens qu'elles ont au sein des communautés filmées.

ÍNDICE

Mots-clés: cinéma, Colombie, alternatif, marginal, Indien, afro-colombien, sud-ouest colombien Palabras claves: cine, Colombia, alternativo, marginal, indígena, afrocolombiano, suroccidente colombiano

\section{AUTOR}

ANGÉLICA MATEUS MORA

Université François-Rabelais de Tours. Laboratoire ICD - EA 6297. 